\title{
The Coordination Imperative for MNE: Empirical Evidence from Foreign Operations in Greece
}

\author{
Dimitris Manolopoulos \\ American College of Greece \\ E-Mail: dman@acgmail.gr
}

\begin{abstract}
Globally, Multinational Enterprises (MNEs) are increasingly focusing on devising strategies in order to balance between the local responsiveness at the subsidiary level and the international integration of operations for global competitiveness. It is against this background, the research studies focusing on the need for evolving effective coordination functions within the multinational network are gaining importance. The present research study makes an attempt to investigate the prevalence of the specific coordination mechanisms in the management of MNEs' activities in Greece and relates them to the underlying corporate culture, relevant information technology mechanisms and the intrinsic organizational architectures so as to serve as valuable tool for managing the interdependencies among the MNE subunits. A survey instrument (questionnaire) was administered to a sample size of 317 foreign firms in Greece to gain insights in to the various factors that determined the use of the appropriate coordination mechanisms so as to manage the interdependencies between HQs and subsidiaries. Multiple regression method was used for our empirical analysis and the results supported the hypotheses put forward in the research design. Our findings further demonstrated that MNEs in Greece manage coordination by tailoring the appropriate instruments to the specific mandates assigned to their subsidiaries thereof.
\end{abstract}

Keywords: Mnes, Greece, Integration, Control, Coordination Mechanisms

\section{INTROUDUCTION}

There is a continuous interest in the subject of integrating the activities carried out 
by the different geographically dispersed and goal-disparate subunits of MNEs (multinational enterprises) in order to deal with the simultaneous effect of the increased globalization of most industries and the responsiveness to distinctive host markets needs (Bartlett \& Ghoshal, 1987a; Doz, 1987). According to Cray (1984), the successful integration of MNE subunits into the whole network operations depends mainly on the manipulation of two complementary processes: coordination and control. There are two streams of research examining the extent and intensity of MNE coordination and control over its subsidiaries: one is centered on the network as a whole (Bartlett \& Ghoshal, 1989), while the other is focused on contextual issues related directly to subsidiaries (Nohria \& Ghoshal, 1997; Gupta \& Govindarajan, 1991). Concerning the latter, most empirical evidence is provided for the global integration of specific business functions (Kim et al., 2003), and especially R\&D (research and development) operations (Asakawa, 2001; Reger, 1999) and sales (Cespedes, 1991). Although existing literature has highlighted the importance of the coordination function within organizations, there is little systematic evidence on the factors that determine the use of different coordination and control mechanisms, under the perspective of subsidiaries' overall strategy (a notable exception is the work of Martinez \& Jarillo, 1991).

Drawing upon a unique sample of 112 subsidiaries located in Greece, the primary objective of this research is to provide insights upon this identified gap in the literature and determine the basic coordination patterns existing in the management of Headquarters (HQs) - subsidiary relationships. In particular, we attempt to identify and classify the mechanisms through which coordination is occurred and investigate the impact of specific contingency factors (subsidiaries' strategic and organizational characteristics) in determining the coordination models adopted for the efficient integration and control of foreign operations.

The paper differs from the relevant existing literature in a variety of ways. First, our results are obtained from subsidiaries' responses and not the HQs. The majority of research undertaken in related issues has been done at the level of the parent firm (e.g. Asakawa, 2001; Belderbos, 2001; Odagiri \& Yasuda, 1996; Edstrom \& Galbraith, 1977). Only a very limited number of studies have examined the determinants and characteristics of MNE integration at the level of subsidiaries (Ambos \& Reitsperger, 2002; Harzing, 2001); and these are mainly focused on specific issues. However, when the research emphasis is placed on the effective coordination and control of those organizational units that may ascribe MNEs with value-added activities, the importance 
given to HQs is not quite attenuated, since decisions that will respond successfully to the global integration and local responsiveness should be better analyzed at the subsidiary level (Prahalad \& Doz, 1987). Second, a new classification for intra-MNE coordination mechanisms is proposed. Third, in relation to MNEs' sector of activities, literature provides evidence for the coordination of specific industrial settings, such as electronics, chemicals and pharmaceuticals (e.g. Asakawa, 2001; Kuemmerle, 1999; Reger, 1999). In this paper, "non-globalized" sectors are also investigated. Finally, this is the first time that such an analysis is presented in international literature for Greece per se. This contribution of our research is considered very important, because since Greece had experienced similar economic characteristics in association with the ten countries that became members of the EU (European Union) during the enlargement procedure, an interesting implication of this analysis is the emerging potential of foreign subsidiaries located in Greece to upgrade their strategic roles into more sophisticated regional representatives of their respective groups.

The paper is organized in the following manner: the second section reviews the literature exploring coordination mechanisms. Following that, we propose a new theoretical framework for classification. In the next sections, we develop our hypotheses, lay down the methodology of the study and present the sample characteristics. Afterwards, we define and operationalize the dependent and independent variables used in this research, present and discuss the empirical results. In the last section we conclude, by putting our findings in a wider strategic and managerial perspective. Limitations of the study and directions for future research are furthermore acknowledged.

\section{LITERATURE REVIEW AND THEORETICAL DEVELOPMENT}

The challenge behind MNEs' expansion in new markets is that the more committed they are to operate globally; the more complicated become the efficient integration of their geographically dispersed subunits. Since a firm's internationalization procedure is path dependant and evolves through time (Eriksson et al., 2000; Johanson \& Vahlne, 1990), new challenges for the management of various interdependencies are expected to occur. As a result, MNEs should identify the appropriate mechanisms in order to exert control and coordinate the activities of their subsidiaries. Coordination within organizations is usually conceived as the integration of different activities in order to accomplish a collective set of tasks (Van de Ven et al., 1976), or as a set of activities that bind together individual efforts toward a common objective (Fayal, 1949). Accordingly, 
coordination mechanisms could be defined as the administrative procedures used to integrate work-related processes and the organizational functions that orient individual activities towards the aims of the corporation.

Early work carried out during the sixties and seventies hypothesized a one-to-one direct relationship between the different kinds of organizational dependencies and coordination mechanisms (Thompson, 1967; Galbraith, 1973; Van de Ven et al., 1976; Mintzberg, 1979). According to this foundation, coordination is mainly achieved through the use of hierarchal solutions (i.e. centralized decision-making, formalization and standardization). In the early eighties, McCann and Galbraith (1981) proposed a two-bytwo matrix, showing the conditions under which organizations will choose to coordinate by rules, mutual adjustments, hierarchical structures or a matrix structure. More recent developments (in the late eighties and thereafter) suggest two generic types of coordination, namely formal hierarchical structures and informal lateral relations. Martinez and Jarillo (1989), for example, have developed a comprehensive classification framework for the coordination function (coordination by plan and coordination by feedback), referring to five categories of "structural" or "formal" mechanisms (departmentalization, centralization or decentralization, formalization or standardization, planning, output and behavior control) and three types of "informal" mechanisms (lateral ties, informal communications and socialization). Birkinshaw (1996) employed the concepts of centralization, socialization and formalization in order to evaluate the configuration of international activities of innovative and differentiated subsidiaries, while Harzing's (2000) four-fold classification was tested against the different types of MNEs. Wolf (1996), Reger (1997) and Kim et al. (2003) provided theoretical insights and empirical evidence for the coordination mechanisms occurred at departmental level, emphasizing mostly on R\&D, manufacturing and marketing.

Based on the previous relevant literature, a five-fold classification for coordination mechanisms is proposed here. The taxonomy of instruments into five mechanisms was elaborated along four distinctive dimensions so as to ascribe uniformity in the analysis. The first refers to the degree of mechanism formality, as the latter is defined by Barnard (1968), in relation with formal and informal organizations. The second refers to the degree of human interaction in the whole integrative procedure, in the sense that mechanisms could be either in favor of personal communication among individual agents or integration through "technocratic/bureaucratic systems". The third incorporates the time dimension of organizational goals, ascribing to the mechanisms a permanent, 
periodic or a temporary character. The last distinguishes among standardized, scheduled, and unsystematic interactiveness.

\section{Formal impersonal coordination mechanisms}

The main feature of "formal mechanisms" is that they have an impersonal and structural character, since they yield to detach the process of aligning decisions and actions from the human being. In those mechanisms, no direct intervention and/or personal interaction between different agents actually takes place. The aim of formal impersonal coordination mechanisms is the establishment of standardized procedures and the formal channeling of individuals' activities. In this broad category, we can include the concept of standardization, the use of formal reporting systems and work manuals and the planning and control of results, as a sub category of output control. The common characteristic of all those instruments is that they pre-specify the expected behavior of individuals (Harzing, 2000).

\section{Centralized interpersonal coordination mechanisms}

This set of mechanisms denotes the idea of some kind of hierarchy in the strategic procedure within the context of an organization. Instruments which are in favor of periodic, compatible to organizational hierarchy, personal interaction between managers and personnel or between subsidiaries and HQs, fall within this category. Centralized interpersonal coordination mechanisms are usually expressed through two main channels: the international transfer of managers and the cross-border visits. Both instruments include the delegation of managerial authority from one subunit to another for a defined time period so that a direct co-work of home country, host country and third country, when necessary, nationals occur. These mechanisms should have a dynamic dimension since their overall purpose targets at the organizational development (Harzing, 2001).

\section{Informal interpersonal coordination mechanisms}

Informal interpersonal coordination mechanisms constitute the third category. These mechanisms refer to some elements which can be characterized as either self-imposed or can be referred to the inner departmental relations in a way that are not a definite part of the organizational structure, but they are used in a rather temporary and unsystematic basis. They can include the formation of teams with limited and precise lifetime and strategic projects. The novelty of this category is that it runs crosswise to the formal 
organizational structure and overlay the hierarchy (Wolf, 1996). The impact of those mechanisms on the efficient coordination is well founded in the literature (e.g. Allen, 1997), however, they have received very little attention (Bouty, 2000).

\section{Social (Cultural) coordination mechanisms}

The importance of social coordination mechanisms emerges from the fact that as global competition intensifies, MNEs should establish strong business relationships with a culturally diverse set of employees, business practices and networks. In this regard, the role of common shared language and corporate culture is critical in the sense that they form a pattern of organizational integration which transcends the enterprise's component entities. The role of culture and language as coordination instruments is even more important if we also consider that a large proportion of internal information exchanges take place between individuals with different language, values and ethics.

\section{Informal IS (Information Systems) coordination mechanisms}

IS (Information Systems) as a set of coordination mechanisms comprises an attempt to link technological and organization advances in enterprises. Since contemporary MNEs consist of complex organizations, that require efficient scanning for effective decision making (in 1979 Aldrich argued that "scanning" could provide the firm with the desired "competitive edge"), IS are said to have a major impact on the coordination of HQs-subsidiary relationships (Sawhney \& Prandelli, 2000). IS devices, such as electronic mail, corporate and public databases, fax and video-conferencing are considered to be some of the driving forces of internationalization. These mechanisms of "control through data management" (Doz \& Prahaland, 1984) have a rather impersonal status since they are mainly used when large volume of information can be easily analyzed and interpreted without extensive face-to-face communications (Kim et al., 2003).

\section{FORMATION OF HYPOTHESES}

The main purpose of our research is to provide insights on the factors and contextual influences that determine the use of the appropriate coordination mechanisms in the management of interdependencies between HQs and subsidiaries. Apparently, any given HQs - Subsidiary relationship is likely to exhibit elements of coordination and control from all the categories at the same time. In this paper, we argue that the above concepts have rather complementary roles in the integrative function; therefore their relationship is 
expected to be positive. Our empirical model is centered on the potential association between mechanisms and subsidiary characteristics (subsidiary roles and degree of autonomy, in-house R\&D units, age, size, export intensity); controlling for MNEs' country of origin and industry factors.

\section{Subsidiary roles and characteristics}

Degree of Centralization - Subsidiary Roles: Centralization is connected with decision-making diffusion, the extent to which decision-making is concentrated in a single point or diffused throughout the organization (Pugh et al., 1968). As an indicator for the extent of centralization, idiosyncratic MNEs strategies and distinctive subsidiary roles can be examined (Govindarajan, 1988; Murray, 1988). In this survey, the variable employed was that of the different roles a subsidiary can assume. There exists a wide literature focusing on the different strategic mandates assigned to subsidiaries within MNE operations (e.g. White \& Poynter, 1984; Bartlett \& Ghoshal, 1987b; Martinez \& Jarillo, 1990; Taggart, 1997). The present study distinguishes among three subsidiary roles, namely Truncated Miniature Replica, Rationalized Product Subsidiariy and Product Mandate. This represents a revised version of the role categorization originally initiated by Canadian scholars and their research into centers of excellence (White \& Poynter, 1984). According to this classification, a TMR (Truncated Miniature Replica) produces and markets some of the parent's product lines in the host country. The degree of a TMR's product adaptation is limited, its managerial needs are relatively standardized and the strategic orientation of this subsidiary type is extensive centralized. Therefore, for TMRs a low degree of responsiveness and a high degree of integration is anticipated. RPS (Rationalized Product Subsidiary) produces limited parts of the group's current range of final products, supplies component parts for assembly by other group subsidiaries, or performs a particular stage in a vertically integrated production process. In this regard, its aim is to optimize the more static dimension of efficiency by achieving economies of scale, or by allowing the manufacture of particular components in locations that are especially favorable in terms of costs and relevant inputs. Finally, PM (Product Mandate) is assigned with the production of differentiated products and is characterized by an increased individualism within the MNE network. Among all roles, PMs achieve the most effective evolution of a number of distinctive but complementary strands in their technological scope and product range. For this type of subsidiary, diversity, interpersonal feedback and network creation is considered critical for successful mission 
accomplishment. In line with the analysis above, the expected relationships among control, integration and the roles of subsidiaries is presented in the following Table.

Table 1 Integration and Control among Different Subsidiaries’ Roles

\begin{tabular}{|c|c|c|c|c|c|}
\hline Roles of Subsidiaries & $\begin{array}{l}\text { Relation } \\
\text { with HQs }\end{array}$ & $\begin{array}{c}\text { Expected } \\
\text { Degree of } \\
\text { Integration }\end{array}$ & $\begin{array}{c}\text { Final } \\
\text { Product/Process }\end{array}$ & Role & $\begin{array}{c}\text { Expected } \\
\text { Degree of } \\
\text { Control }\end{array}$ \\
\hline $\begin{array}{l}\text { Production of Well } \\
\text { Established Products (TMR) }\end{array}$ & Tight & High & Standardized & Static & High \\
\hline $\begin{array}{l}\text { Production and Export part } \\
\text { of the Established Product } \\
\text { Range or Specialized } \\
\text { Products (RPS) }\end{array}$ & $\begin{array}{l}\text { Tight - } \\
\text { Moderate } \\
\text { Autonomy }\end{array}$ & High & Standardized & $\begin{array}{l}\text { Static - } \\
\text { Moderate }\end{array}$ & Average \\
\hline $\begin{array}{l}\text { To Develop, Produce and } \\
\text { Market New Products (PM) }\end{array}$ & Autonomy & Low & Differentiated & Dynamic & Low \\
\hline
\end{tabular}

Source: Author's survey

In our research we hypothesize that the extent centralization comprises a very decisive factor in managing HQs-Subsidiary interdependencies. It is expected that in case of an increased decentralized subsidiary role, HQs use of formal control will decrease and vice versa. Therefore, the following assumptions are formed:

Hypothesis 1a: There will be a positive relationship between TMR and RPS and the importance ascribed to formal impersonal, social and informal IS coordination mechanisms

Hypothesis 1b: There will be a positive relationship between PM and the importance ascribed to interpersonal (centralized and informal) mechanisms

Strategic Decision Making Autonomy: Although literature suggests that (de) centralization and autonomy have a high positive correlation (Brock, 2003) their meaning is substantially different. Autonomy of an organization measures the extent of decisionmaking authority (Brock, 2003). On the contrary, centralization refers to the locus of the decision-making authority. In order to identify subsidiaries' extent of autonomy, the 
variable employed here was that of decision-making autonomy in the strategy formulation. There is an assumption in the MNE literature that more "autonomous" subsidiaries enjoy a lower degree of interdependence compared to subsidiaries assigned with the production of standardized products (Martinez \& Jarillo, 1990). Moreover, more autonomous subsidiaries tend to create linkages with a multiplicity of host environment entities (Almeida \& Kogut, 1997). This kind of interaction may require the spontaneous analysis and assessment of a large volume of information. Furthermore, literature indicates that interpersonal and informal coordination mechanisms would be more appropriate in the whole MNE integrative procedure in order to communicate the differentiated competencies that would potentially give the subsidiary an upgrading status in the context of its group (Pearce, 1999). It is anticipated that:

Hypothesis 2a: There will be a positive relationship between more autonomous subsidiaries and the importance ascribed to IS systems, informal and centralized interpersonal coordination mechanisms

Hypothesis 2b: There will be a positive relationship between less autonomous subsidiaries and the importance of formal impersonal and social coordination mechanisms

In-house $R \& D$ Activities: The effective application of technological resources and advancements worldwide may enhance a corporation's involvement in global innovative activities, which in turn, may generate distinctive capabilities for the whole MNE group (Birkinshaw et al., 2002). The more advanced in-house source of subsidiary technology would be the results of its own R\&D laboratory (Papanastassiou \& Pearce, 1994). Indeed, a growing steam of empirical evidence has suggested that MNEs have assigned substantial R\&D tasks to their foreign affiliates (Reger, 1999; Cheng \& Bolton, 1993). Implementation of overseas $R \& D$ activities lead multinationals to operate in a context which provides a scope that exceeds beyond that needed in the more traditional export substituting roles. More than most of corporate functions, $R \& D$ requires a higher degree of autonomy to fulfill its charter to "create the future" (Fisher \& Behrman, 1979). We would expect that the existence of R\&D imply the development of interactive networks and personal contacts in order the acquired advantage among research, production and marketing activities would be totally exploited. In this case, the need for flexibility outweighs the need for predictability so that more complex technologies should be associated with lower levels of integration. Bringing all this evidence together, we expect that: 
Hypothesis 3a: R\&D subsidiaries will be positively associated with the use of person-oriented (centralized and informal) coordination mechanisms compared to subsidiaries without $R \& D$ departments

Hypothesis 3b: Subsidiaries without R\&D departments will be positively associated with the use of formal impersonal, social and IS coordination mechanisms compared to $R \& D$ subsidiaries

Size of Subsidiary: Existing research reveals conflicting evidence between highly centralized integration patterns and subsidiary size. Hakanson (1981) argued that large organizational units raise the autonomy of subsidiary managers. In a similar vein, Gates and Egelhoff (1986) suggested that a larger subsidiary may operate more independently, therefore is more autonomous. This view was supported by Ghauri (1992); but not by the study conducted by Wolf (1994). Given this ambiguity, the size of the subsidiary may affect the proposed model and yet the direction and nature of this effect is not known. Consequently, it is considered important to control for subsidiary size. Overall, we expect that large units consist of different functional teams with varied power and distinctive research interests. In that sense, large units may have the potential to resist formalized structures and centralized decision-making. We are seeking evidence on these issues by putting the following hypothesis to test:

Hypothesis 4: The size of subsidiary will be positively associated with the use of person-oriented (centralized and informal) coordination mechanisms

Age of Subsidiary: Hedlund (1984) supported that subsidiary's age may affect the mechanisms used by HQs to control its activities. Firm's ability to learn from overseas operations is a prerequisite for the dynamic evolution of the whole group. By the course of time, MNEs accumulate knowledge on how to apply tacit knowledge across borders in different locations (Penner-Hahn, 1998, Kogut \& Zander, 1995). It can also be argued that firms operating in a foreign location for a number of years would be better "embedded" to the distinctive characteristics of the host environment and would have greater incentive to invest in more differentiated products, having as a fundamental prerequisite the acquisition of all available inputs. According to Bjorkman and Piekkari (2002), subsidiary age seems to contribute to the use of social and person-oriented mechanisms. Therefore, it is expected that:

Hypothesis 5: Centralized interpersonal and social coordination mechanisms are positively related with the age of the subsidiary 
Export intensity: At the subsidiary level, evidence suggests that high export intensity may imply that subsidiaries are mandated to supply a wider regional area rather than being limited to serve the host country needs (Belderbos, 2001). This implies the development of networks in respect of markets' servicing and sourcing (Caves, 1996). In order these networks to coordinate smoothly, they require standardized procedures and the exchange of a large volume of information. We argue that:

Hypothesis 6: The export propensity of a subsidiary will be positively associated with formal impersonal and informal IS coordination mechanisms

\section{Subsidiary's sector and HQs home country}

A set of control variables (sector and country of HQs origin) are included in the analysis in order to control for possible extraneous variation.

Country of Origin: Research suggests that the country of origin can influence the roles and responsibilities of a MNE subsidiary (Bartlett \& Ghoshal, 1990); an observation that has been supported by a study of foreign subsidiaries in the UK (Papanastassiou \& Pearce, 1997). The country where the HQs are located can also affect the skills of the MNE, influencing the subsidiary's strategic choices (Casson, 1997). Evidence provided by Ambos and Reitsperger (2002), indicates a positive relationship between distance and total control. Moreover, European corporations have a tendency to rely more on social, person oriented coordination mechanisms than their American counterparts (Egelhogg, 1984; Hedlund, 1984). According to Cray (1984), subsidiaries located at a long administrative distance from the center of the organization will be subjected to higher levels of control and lower levels of coordination. Kotabe and Omura (1989) have found that Japanese MNEs engage more intensively centralized coordination activities than Western enterprises do, even though there is a tendency for both Japanese and US MNEs to rely on an increasing degree of social mechanisms in managing their European units (Lehrer \& Asakawa, 1999). It is expected that:

Hypothesis 7: The use of formal impersonal mechanisms will be positively related to geographical distance between HQs and subsidiaries

Industry: It is expected that "globalized" sectors would require for highly integrated networks. Bartlett and Ghoshal (1992) supported that centralization is the dominant control mechanisms for corporations activating in global industries. We hypothesize that in global industries the demand of products displays different elasticity for different 
local/regional markets because of its widely heterogeneous determinants, therefore the need for integration and control is even stronger. Thus, the following hypothesis is formed:

Hypothesis 8: Subsidiaries operating in "global" industries will use more intense formal impersonal, social and IS coordination mechanisms in comparison with subsidiaries activating in "non global" industries

\section{SAMPLING, DATA AND METHODS}

\section{Questionnaire design and target sample}

This research is part of a wider survey concerning the strategic bases for MNEs' expansion into the economy of Greece. Information regarding the sample was collected via a unique, nationwide, questionnaire-based postal survey between 2002 and 2004. The study uses data, issued by the ICAP (International Capital) database, for the subsidiaries of foreign firms established in Greece in 2000. A total of 317 subsidiaries were included in ICAP's database. The industries involved include pharmaceuticals, chemicals, electronics and IT, machinery, food and beverage, textiles, services and other manufacturing. Major countries of inward investment include the U.S., Japan, EU and other European countries.

The whole questionnaire which was sent to subsidiaries consists of 5 sections and 27 questions in total. In this paper, 10 questions were used in order to identify the country of HQs origin, the roles and strategic autonomy of subsidiaries, their size, age, sector, technological capabilities, the export intensity and the coordination mechanisms used (see Appendix I). The questionnaire sent to subsidiaries was developed through a threestage process. Firstly, two academicians and a professional consultant, who suggested improvements in wording and advice on layout, reviewed the draft questionnaire. Secondly, following a major revision of the questionnaire, it was sent out to five chief executive officers (CEO) of subsidiaries operating in different industrial sectors. We had arranged an interview with them where we had analytically explained the structure and purpose of our research; asking to provide us with insights that would fulfill the scope of the survey. In most cases corrections were similar. After the second revision, the questionnaire was sent to four firms chosen by their country of HQ origin for the final pre testing. Wording and structure of the questionnaires were not improved, although two 
more questions were added.

\section{Sample size and data collection methods}

An initial mailing and three follow-up mailings resulted in 112 responses. Thus, the response rate is approximately 36\%, higher than the minimum recommended level of 20\% (Agarwal \& Ramaswami, 1992). It is considered to be perfectly acceptable in comparison to similar mail surveys. Table 2 summarizes the response rates and the number of respondents by industry and country of HQs location. Following Lin (2003), to examine potential non-response bias we compared respondents and the population on three variables (this refers to the whole questionnaire): number of employees, sales and the age of the corporation. No statistical significant differences between respondents and non-respondent firms have been observed.

Table 2 Number of respondents by sector and country of HQs

\begin{tabular}{lccc}
\hline \multicolumn{1}{c}{ Sector } & Total Sample & $\begin{array}{c}\text { Number of } \\
\text { Respondents }\end{array}$ & Response Rate \\
\hline Pharmaceuticals & 45 & 29 & $64.44 \%$ \\
Chemicals & 42 & 24 & $57.14 \%$ \\
Electronics and IT & 28 & 11 & $39.29 \%$ \\
\multicolumn{1}{c}{ Globalized } & 115 & 64 & $55.65 \%$ \\
Machinery & 31 & 17 & $54.84 \%$ \\
Other Manufacturing & 37 & 16 & $43.24 \%$ \\
Food and Beverages & 39 & 15 & $38.46 \%$ \\
\multicolumn{1}{c}{ Not Globalized } & 107 & 48 & $44.86 \%$ \\
Various & 95 & 0 & $0.00 \%$ \\
Total & 317 & 112 & $35.33 \%$ \\
\hline
\end{tabular}


Table 2 Number of respondents by sector and country of HQs (Continued)

HQs Country of Location Total Sample $\begin{gathered}\text { Number of } \\ \text { Respondents }\end{gathered}$ Response Rate

\begin{tabular}{lccc}
\hline EU Countries & 112 & 34 & $30.36 \%$ \\
Other European Countries & 47 & 22 & $46.81 \%$ \\
Japan & 39 & 14 & $35.90 \%$ \\
US & 85 & 31 & $36.47 \%$ \\
Rest of World & 34 & 11 & $32.35 \%$ \\
Total & $\mathbf{3 1 7}$ & $\mathbf{1 1 2}$ & $35.33 \%$ \\
\hline
\end{tabular}

\section{Methodology}

The hypotheses identified above are tested by using regression analysis estimated by logistic regression. The general model to examine the relationship between the different coordination instruments and the various explanatory and control variables is provided by the following equation:

$=\operatorname{Logit}(\mathrm{p})$

$=a_{0}+a_{1} X_{1}+a_{2} X_{2}+a_{3} X_{3}+\ldots+a_{v} X_{v}(1)$

where:

$\mathrm{x}$ denotes the independent/explanatory and control variables.

Ordered logit was applied as an econometric technique since our dependent variable (coordination mechanisms) is a qualitative one, ascribed with ascending degrees of importance. In this case $\boldsymbol{y}$ is not a quantity, but nevertheless a larger value of $\boldsymbol{y}$ means more, or better. Therefore $\boldsymbol{y}$ is a qualitative polychotomous dependent variable. If the qualitative dependent variable was only polychotomous, literature suggests that we could use linear regression models. Since it is also ordinal, linear models should be rejected because they would misspecify the data generating process in assuming that there is no order in the different categories that $\boldsymbol{y}$ could take. Thus, linear models would consider the difference in $\boldsymbol{y}$ between a 1 and a 2 as equivalent to the difference between a 2 and a 3 and a 3 and a 4 . Ordered logit model is used for estimation in the context of an ordinal polychotomous dependent variable. While taking into account the existence of a ranking, ordered logit also assumes that the size of the difference between any two adjacent ratings is not known but does not matter to the carrying out of the analysis. The model is 
suited to discrete data, it is unhindered by large numbers of ties and it circumvents problems associated with heterogeneity (Han \& Hausman, 1990). An ordered logit model is built around a latent regression in the same manner as the binomial logit model and has the following form:

$$
y_{i}^{*}=\beta_{i}{ }^{\prime} x+u_{i}(2)
$$

where:

$\beta_{i}$ are the estimated coefficients,

$\mathrm{u}_{i}$ is a normally distributed error term,

$\boldsymbol{y}_{\boldsymbol{i}}{ }^{*}$ is unobserved and what we observe comes in the following form: When $\boldsymbol{y}^{*}$ takes on the values $0,1,2, \ldots, \mathrm{m}$, the ordered logit model estimates a set of coefficients for each of the $\mathrm{m}-1$ points at which the dependent variable can be dichotomized.

The relatively small sample made us relax the usual 0.05 criterion for statistical significance to the 0.1 level (in various surveys, the criterion for statistical significance is relaxed to 0.2 with still effective significant prediction, Chang, 2003). In order to have more accurate results, we run our regressions using dummies for the sector and country of origin of subsidiaries. By doing so, it helps to identify differences across markets and geographical locations with similar characteristics. Alternatively, binomial and ordered probit models were used by dividing coordination mechanisms into two categories (important and not so important) and transforming the dependant variable in a binary dummy variable taking value one if the mechanism is considered important by the subsidiary and zero otherwise, but they proved to be slightly inferior; providing at the same time very similar results.

\section{Operationalization of variables}

Dependent Variables: The dependent variables in our survey comprise of eight, well identified in the literature, coordination instruments. Subsidiaries were asked to rate on a scale from 4 (very important) to 1 (not taken under consideration) the use of the specific instruments to their operations. As indicators of formal impersonal coordination mechanisms, formal reporting systems and control of output were selected. International transfer of managers and cross-border visits are used as indicators in order to evaluate the importance ascribed to centralized interpersonal mechanisms, whereas for informal interpersonal, strategic and training teams were selected. For testing the importance of social mechanisms, we focus on corporate culture. The use of corporate networks provides a proxy to evaluate the importance IS coordination mechanisms. 
Explanatory Variables: The core of the paper is to test whether the use of specific coordination mechanisms is related to the differentiated roles subsidiaries can assume within MNE operations. Other subsidiary-related characteristics are tested as well. Strategic decision-making autonomy measures the degree to which the focal subsidiary collaborates in defining its own strategy, mainly whether decisions are taken by the subsidiary alone, in consultation with the HQs or emanate by the HQs (Tavares \& Young, 2002). Subsidiary age (number of years since the establishment of the subsidiary in the host country) and size are investigated as relevant predictors of the use of appropriate coordination mechanisms. As proxy of size, subsidiaries were asked to state the number of personnel and the volume of sales/turnover. Personnel as indicator of firm size is used by Mittelstaedt et al. (2003) and volume of sales are indicators of firm performance is identified in the work of Gaba et al. (2002), among others. Subsidiaries were also asked if they implement $R \& D$ activities and which is their export intensity. Export intensity is the percentage of exports of the subsidiary vis-à-vis the subsidiary's total production.

Control Variables: Home country variables are included in the model. Corporations were classified according to the country of HQs location. Subsidiaries whose HQs are located in Japan are used as a dummy variable. Mapping the sectoral dimensions required to create a horizontal classification covering 6 sectors: pharmaceuticals, chemicals, electronics and IT, machinery, other manufacturing and food and beverages. The next step was to categorize the above sectors into globalized and non-globalized. Based on the work of Makhija et al. (1997) and Morrison and Roth (1992), chemicals, electronics and pharmaceuticals comprise globalized industries. An industry dichotomous variable (GLOBSEC) was used differentiating "globalized" and "non-globalized" sectors (the same taxonomy was used by Tavares \& Young, 2003). It should be noted that global industries are not dealt with the "academic" definition of a global configuration, but rather with the scope of examining the supply of differentiated product to host markets. Food and beverages were classified in the "not-globalized" sector, following the work of Korbin (1994) and Porter (1986). The dummy variable used for the sectoral analysis was "non globalized industries".

Explanatory and control variables are defined and operationalized in the following Table: 
Table 3 Variables' description

\begin{tabular}{|c|c|c|}
\hline Variables & Type $^{\mathbf{a}}$ & Operational definition \\
\hline \multicolumn{3}{|l|}{ Role of Subsidiary } \\
\hline $\begin{array}{l}\text { Truncated Miniature } \\
\text { Replica (TMR) }\end{array}$ & $\mathrm{L} / \mathrm{D}$ & $\begin{array}{l}\text { Subsidiary that produces standardized products } \\
(4=\text { only role, } 3=\text { main role, } 2=\text { secondary role, } 1=\text { not } \\
\text { part of role) }\end{array}$ \\
\hline $\begin{array}{l}\text { Rationalized } \\
\text { Product Subsidiary } \\
\text { (RPS) }\end{array}$ & $\mathrm{L} / \mathrm{D}$ & $\begin{array}{l}\text { Subsidiary that specialize its production in specific } \\
\text { products or component parts of the final product } \\
\text { ( } 4=\text { only role, } 3=\text { main role, } 2=\text { secondary role, } 1=\text { not } \\
\text { part of role) }\end{array}$ \\
\hline $\begin{array}{l}\text { Product Mandate } \\
(\mathrm{PM})\end{array}$ & $\mathrm{L} / \mathrm{D}$ & $\begin{array}{l}\text { Subsidiary that produces differentiated products } \\
(4=\text { only role, } 3=\text { main role, } 2=\text { secondary role, } 1=\text { not } \\
\text { part of role) }\end{array}$ \\
\hline $\begin{array}{l}\text { Degree of decision } \\
\text { making autonomy }\end{array}$ & $\mathrm{L} / \mathrm{D}$ & $\begin{array}{l}\text { Degree of subsidiary's strategic authority } \\
(4=\text { decisions mainly taken by the subsidiary's BoD, } \\
3=\text { decisions mainly taken by the subsidiary's BoD } \\
\text { after consulting HQs, } 2=\text { decisions mainly taken by } \\
\text { HQs after consulting the subsidiary, 1=decisions } \\
\text { mainly taken by HQs) }\end{array}$ \\
\hline \multicolumn{3}{|c|}{ Subsidiary characteristics } \\
\hline $\mathrm{R} \& \mathrm{D}$ & $\mathrm{B} / \mathrm{D}$ & $\begin{array}{l}1=\text { subsidiary undertakes in-house R\&D activities, } \\
0=\text { otherwise }\end{array}$ \\
\hline Age & $\mathrm{C}$ & $\begin{array}{l}\text { Age of Subsidiary (Number of years the subsidiary } \\
\text { has been established in Greece) }\end{array}$ \\
\hline Sales & $\mathrm{C}$ & $\begin{array}{l}\text { Total volume of subsidiary's gross sales expressed } \\
\text { in million Euros }\end{array}$ \\
\hline Personnel & $\mathrm{C}$ & $\begin{array}{l}\text { Employment (Number of employees in the } \\
\text { subsidiary) }\end{array}$ \\
\hline Exports & $\mathrm{B} / \mathrm{D}$ & $\begin{array}{l}1=\text { Over the } 10 \% \text { of subsidiary's overall production } \\
\text { is exporting, } 0=\text { otherwise }\end{array}$ \\
\hline \multicolumn{3}{|l|}{ MNE Home country } \\
\hline EU & $\mathrm{B} / \mathrm{D}$ & $1=$ parent from $\mathrm{EU}, 0=$ otherwise \\
\hline OtherEur & $\mathrm{B} / \mathrm{D}$ & $\begin{array}{l}1=\text { parent from other European country, } \\
0=\text { otherwise }\end{array}$ \\
\hline Japan & $\mathrm{B} / \mathrm{D}$ & $1=$ parent from Japan, $0=$ otherwise \\
\hline US & $\mathrm{B} / \mathrm{D}$ & $1=$ parent from USA, $0=$ otherwise \\
\hline Rest of World & $\mathrm{B} / \mathrm{D}$ & $\begin{array}{l}1=\text { parent from other country except the above } \\
\text { mentioned, } 0=\text { otherwise }\end{array}$ \\
\hline GlobSec & $\mathrm{B} / \mathrm{D}$ & $\begin{array}{l}1=\text { Firms belong to globalized industries, } \\
0=\text { otherwise }\end{array}$ \\
\hline
\end{tabular}

${ }^{a}$ Binary (B); / Likert - Type (L); / Continuous (C); / Discrete (D) 


\section{RESULTS AND DISCUSSION}

The regression results are reported in Table 4. Eight econometric tests were run, where the dependent variable represent the different coordination mechanisms defined and operationalized in the previous section. Independent variables include industry and country dummies and a set of quantitative and qualitative variables referring to subsidiary characteristics. Five, out of eight full models were significant at $p<0.001$. The descriptive statistics of the independent variables used (means, standard deviation and Pearson correlation coefficients) are presented in Appendix II. Ordered logit model does not produce an $R_{\text {adj }}^{2}$ statistic. The model has a high explanatory power with a high and highly significant $\chi^{2}$. Tests on ordered logit models provide evidence that omitted uncorrelated explanatory variables and neglected heteroscedasticity may generate inconsistent parameter estimates in this type of models (Kiefer \& Skoog, 1984). To test for these misspecifications, an artificial regression based on LM (Lagrange Multiplier) test was used. According to Murphy (1996), LM tests have good small sample properties, which is the case in this paper. In this paper, no serious problem for the model was observed.

Overall, the results support the hypotheses we put forward. As expected, TMRs' and RPSs' role is allocated by the HQs, being in that way strongly dependant on group coordination procedures. The statistical positive relationship between these roles and the use of formal impersonal and informal IS coordination mechanisms indicate a high degree of control of subsidiaries' operations. This finding is furthermore reinforced by the statistical significant negative relationship between TMRs and centralized interpersonal coordination mechanisms. On the other hand, the use of person oriented (centralized and informal) mechanisms is well justified in PMs, since, by definition, their functional scope includes the production of new products. In this regard, they seek to establish open communication channels with both the MNE network and the local environment so as to exploit all the available creative inputs.

Against our second set of hypotheses, it seems that more autonomous subsidiaries are assumed to be structured in a more heterarchical fashion. While decision-making authority is restricted to a limited number of individuals in a hierarchy, heterarchies are founded on more participative, flexible and decentralized structures. The statistical positive significant relationship between more autonomous subsidiaries and social, informal and IS coordination mechanisms provide evidence that coordination patterns are developed according to situational requirements and equal participation of all members in problem solving and strategy implementation is allowed. Moreover, our findings indicate 
that the autonomy of decision-makers is even more reinforced when the institutional design allows them access to corporate information processes. Against our hypothesis, a reverse relationship between centralized subsidiaries and corporate culture, as a coordination instrument, is observed. This could be explained by an argument supported by many authors, according to which coordination in hierarchies is conducted through formalized structures, while more autonomous subsidiaries are compensated by a strong organizational cultural integration, which may be viewed as a prerequisite of any selforganized system.

The most striking result is the overall importance of the majority of coordination mechanisms regarding subsidiaries with in-house R\&D departments. This indicates that the effective coordination and control of $R \& D$ subsidiaries is a complex procedure that requires a multifaceted context of coordination mechanisms. The importance ascribed to formal impersonal mechanisms may be explained by using the Quester and Conduit (1996) line of argumentation. According to the latter, the greater the dependency of a parent company on its foreign operations, the greater the risk and the stronger the tendency to centralize all decisions. This is somehow contradictory with the existing literature that supports that HQs rely more on formalized structures and mechanisms when controlling subsidiaries without specialized research capabilities. On the other hand, decentralized $R \& D$ departments are assigned with product or technology adaptations, or even with the task to manufacture completely differentiated products. To that end, person oriented mechanisms are justified as a sophisticated medium of control and exchange of information. In other words, the more a firm's competitiveness depends on the ability to innovate, the more flexible should be the coordination linkage with the parent multinational. Indeed, our evidence is in line with prior research, arguing that informal exchanges across organizational boundaries are of great consequence for innovation (Bouty, 2000). Finally, the positive relationship between IS systems and R\&D subsidiaries is perfectly compatible with the principles of post industrial society, where interactive technologies reduce distances both in time and space, and act as catalysts in effective knowledge sharing and transfer (Sawhney \& Prandelli, 2000). 
Table 4 Regression test on coordination mechanisms 1

\begin{tabular}{|c|c|c|c|c|c|c|c|c|}
\hline & \multicolumn{2}{|c|}{$\begin{array}{c}\text { FORMAL } \\
\text { IMPERSONAL }\end{array}$} & \multicolumn{2}{|c|}{$\begin{array}{l}\text { CENTALIZED } \\
\text { PERSONAL }\end{array}$} & \multicolumn{2}{|c|}{$\begin{array}{l}\text { INFORMAL } \\
\text { PERSONAL }\end{array}$} & \multirow{2}{*}{$\begin{array}{l}\text { SOCIAL } \\
\text { culture }\end{array}$} & \multirow{2}{*}{$\begin{array}{c}\text { IS } \\
\text { network }\end{array}$} \\
\hline & frs & output & tranfers & visits & st & $t t$ & & \\
\hline \multicolumn{9}{|l|}{ SUBSIDIARY ROLES ${ }^{2}$} \\
\hline TMR & $\begin{array}{l}.009 * * \\
(.001)\end{array}$ & $\begin{array}{l}-.990 \\
(.709)\end{array}$ & $\begin{array}{c}.055 \\
(.046)\end{array}$ & $\begin{array}{l}-.621 * \\
(.482)\end{array}$ & $\begin{array}{l}.665 \\
(.515)\end{array}$ & $\begin{array}{l}-.189 \\
(.130)\end{array}$ & $\begin{array}{l}-1.567 \\
(1.201)\end{array}$ & $\begin{array}{c}.003 * * * \\
(.001)\end{array}$ \\
\hline RPS & $\begin{array}{c}.004 * * * \\
(.001)\end{array}$ & $\begin{array}{l}.012 * \\
(.007)\end{array}$ & $\begin{array}{l}-.107 \\
(.082)\end{array}$ & $\begin{array}{l}.880 \\
(.757)\end{array}$ & $\begin{array}{l}.889 \\
(.766)\end{array}$ & $\begin{array}{l}-.994 \\
(.968)\end{array}$ & $\begin{array}{l}.289 \\
(.212)\end{array}$ & $\begin{array}{l}.582 \\
(.339)\end{array}$ \\
\hline PM & $\begin{array}{l}-.212 \\
(.180)\end{array}$ & $\begin{array}{l}.114 \\
(.097)\end{array}$ & $\begin{array}{c}.004 * * * \\
(.001)\end{array}$ & $\begin{array}{l}-.385 \\
(261)\end{array}$ & $\begin{array}{l}.377 * \\
(.265)\end{array}$ & $\begin{array}{c}.412 \\
(.318)\end{array}$ & $\begin{array}{c}.984 \\
(.658)\end{array}$ & $\begin{array}{l}-1.089 \\
(.837)\end{array}$ \\
\hline $\begin{array}{l}\text { STRATEGIC } \\
\text { AUTONOMY }\end{array}$ & $\begin{array}{l}-.456 \\
(.340)\end{array}$ & $\begin{array}{l}-.670 \\
(.520)\end{array}$ & $\begin{array}{l}.091 \\
(.086)\end{array}$ & $\begin{array}{l}.558 \\
(.387)\end{array}$ & $\begin{array}{l}.013 * * \\
(.004)\end{array}$ & $\begin{array}{l}1.086 \\
(.995)\end{array}$ & $\begin{array}{l}.715^{*} \\
(.480)\end{array}$ & $\begin{array}{l}1.304 * \\
(.907)\end{array}$ \\
\hline \multicolumn{9}{|c|}{ SUBSIDIARY CHARACTERISTICS } \\
\hline $\mathrm{R} \& \mathrm{D}$ & $\begin{array}{c}.537 * * * \\
(.104)\end{array}$ & $\begin{array}{c}.937 \\
(.760)\end{array}$ & $\begin{array}{c}.741 \\
(.611)\end{array}$ & $\begin{array}{l}.785 * * \\
(.387)\end{array}$ & $\begin{array}{l}-1.086 \\
(.771)\end{array}$ & $\begin{array}{l}.951 * \\
(.603)\end{array}$ & $\begin{array}{l}.449 * * \\
(.242)\end{array}$ & $\begin{array}{l}1.174 \% \\
(.818)\end{array}$ \\
\hline AGE & $\begin{array}{l}-1.503 \\
(.920)\end{array}$ & $\begin{array}{l}.484 \\
(.311)\end{array}$ & $\begin{array}{l}.087 \\
(.055)\end{array}$ & $\begin{array}{l}-.084 \\
(.041)\end{array}$ & $\begin{array}{l}1.210 \\
(.786)\end{array}$ & $\begin{array}{l}-.316 \\
(.290)\end{array}$ & $\begin{array}{l}.919 \\
(.721)\end{array}$ & $\begin{array}{l}1.330 \\
(.870)\end{array}$ \\
\hline PERSONNEL & $\begin{array}{l}.431 * * \\
(.450)\end{array}$ & $\begin{array}{c}.385 \\
(.204)\end{array}$ & $\begin{array}{c}.760 \\
(.487)\end{array}$ & $\begin{array}{c}.852 \\
(.717)\end{array}$ & $\begin{array}{c}.881 \\
(.663)\end{array}$ & $\begin{array}{l}.725 \\
(.431)\end{array}$ & $\begin{array}{c}.564 \\
(.471)\end{array}$ & $\begin{array}{c}.919 \\
(.861)\end{array}$ \\
\hline SALES & $\begin{array}{l}-.870 \\
(.525)\end{array}$ & $\begin{array}{c}-884 * * \\
(.253)\end{array}$ & $\begin{array}{l}.571 \\
(.486)\end{array}$ & $\begin{array}{l}-.515 \\
(.346)\end{array}$ & $\begin{array}{l}.489 \\
(.441)\end{array}$ & $\begin{array}{l}.776 \\
(.583)\end{array}$ & $\begin{array}{l}.334 \\
(.239)\end{array}$ & $\begin{array}{l}.967 \\
(.786)\end{array}$ \\
\hline EXPORT & $\begin{array}{c}1.427 \\
(1.015)\end{array}$ & $\begin{array}{c}2.770 \\
(1.524)\end{array}$ & $\begin{array}{c}1.786 \\
(1.004)\end{array}$ & $\begin{array}{l}-1.783 \\
(1.663)\end{array}$ & $\begin{array}{c}3.061 \\
(1.991)\end{array}$ & $\begin{array}{l}-.814 \\
(.780)\end{array}$ & $\begin{array}{l}.980 \\
(.866)\end{array}$ & $\begin{array}{c}2.414 \\
(1.980)\end{array}$ \\
\hline \multicolumn{9}{|l|}{ HOME COUNTRY } \\
\hline EU & $\begin{array}{c}1.114 * * \\
(.716)\end{array}$ & $\begin{array}{c}.951 \\
(.779)\end{array}$ & $\begin{array}{l}-.001 * * * \\
(.001)\end{array}$ & $\begin{array}{c}.850 \\
(.780)\end{array}$ & $\begin{array}{c}.480 \\
(.301)\end{array}$ & $\begin{array}{c}-.009 * * \\
(.002)\end{array}$ & $\begin{array}{l}-.550 \\
(.420)\end{array}$ & $\begin{array}{l}-.577 \\
(.490)\end{array}$ \\
\hline OTHER EUROPEAN ${ }^{3}$ & $\begin{array}{l}1.017 \\
(.930)\end{array}$ & $\begin{array}{l}.820 \\
(.580)\end{array}$ & $\begin{array}{l}-700 \\
(.430)\end{array}$ & $\begin{array}{l}-.470 * \\
(.220)\end{array}$ & $\begin{array}{l}.130 \\
(.086)\end{array}$ & $\begin{array}{c}3.004 \\
(2.980)\end{array}$ & $\begin{array}{l}-.991 \\
(.766)\end{array}$ & $\begin{array}{c}2.662 \\
(1.990)\end{array}$ \\
\hline US & $\begin{array}{c}.066 * * * \\
(.008)\end{array}$ & $\begin{array}{c}.341 \\
(.334)\end{array}$ & $\begin{array}{l}-.770 \\
(.529)\end{array}$ & $\begin{array}{l}-.004 * \\
(.002)\end{array}$ & $\begin{array}{c}.615 \\
(.520)\end{array}$ & $\begin{array}{c}.206 \\
(.202)\end{array}$ & $\begin{array}{c}.323 \\
(.248)\end{array}$ & $\begin{array}{c}-.103 \\
(.097)\end{array}$ \\
\hline REST OF WORLD ${ }^{4}$ & $\begin{array}{l}-.980 \\
(.672)\end{array}$ & $\begin{array}{l}.520 \\
(.448)\end{array}$ & $\begin{array}{l}.741 \\
(.450)\end{array}$ & $\begin{array}{l}-.655 \\
(.553)\end{array}$ & $\begin{array}{l}.241 \\
(.155)\end{array}$ & $\begin{array}{l}-.430 \\
(.383)\end{array}$ & $\begin{array}{l}.680 \\
(.477)\end{array}$ & $\begin{array}{l}-.774 \\
(.581)\end{array}$ \\
\hline GLOBSEC $^{5}$ & $\begin{array}{l}-.433 \\
(.406)\end{array}$ & $\begin{array}{l}-.421 \\
(.408)\end{array}$ & $\begin{array}{c}.786 \\
(.531)\end{array}$ & $\begin{array}{l}.601 * \\
(.387)\end{array}$ & $\begin{array}{c}.098 \\
(.081)\end{array}$ & $\begin{array}{c}.950 \\
(.824)\end{array}$ & $\begin{array}{c}.912 \\
(.756)\end{array}$ & $\begin{array}{c}.986 \\
(.778)\end{array}$ \\
\hline F Statistic & $81.37 * * *$ & $84.21 * * *$ & $91.42 * * *$ & $102.25 * * *$ & 1.70 & $107.55 * * *$ & 1.25 & 1.12 \\
\hline Cronbach alpha & 0.76 & 0.71 & 0.68 & 0.72 & 0.59 & 0.80 & 0.67 & 0.61 \\
\hline \multicolumn{9}{|c|}{$*$ significant at $10 \%,{ }^{* *}$ significant at $5 \%, * * *$ significant at $1 \%$} \\
\hline $\begin{array}{l}\text { Notes } \\
\text { 1. Coordination Mecha } \\
\text { frs } \\
\text { output } \\
\text { transfers } \\
\text { visits } \\
\text { st } \\
\text { tt } \\
\text { culture } \\
\text { networks } \\
\text { 2. For full description o } \\
\text { 3. Includes subsidiaries } \\
\text { 4. Includes subsidiaries } \\
\text { 5. Includes Chemicals, }\end{array}$ & $\begin{array}{l}\text { s: } \\
\text { Formal Rep } \\
\text { Output Con } \\
\text { Internatione } \\
\text { Cross Bord } \\
\text { Strategic T } \\
\text { Training Te } \\
\text { Corporate C } \\
\text { Corporate } \mathrm{P} \\
\text { osidiaries rol } \\
\text { n Switzerlan } \\
\text { n Australia, } \\
\text { tronics and I }\end{array}$ & $\begin{array}{l}\text { rting Syste } \\
\text { rol } \\
\text { transfer of } \\
\text { r Visits } \\
\text { ams } \\
\text { Ims } \\
\text { ulture } \\
\text { etworks } \\
\text { s, see Secti } \\
\text { Cyprus, L } \\
\text { anada, Pan } \\
\text { harmaceutic }\end{array}$ & $\begin{array}{l}\text { ms } \\
\text { Managers } \\
\text { on } 4 \\
\text { iechtensteir } \\
\text { ama and So } \\
\text { als. }\end{array}$ & $\begin{array}{l}\text { Luxembour } \\
\text { th Korea. }\end{array}$ & nd Russ & & & \\
\hline
\end{tabular}


Against our forth hypothesis, results are not very explanatory. Statistical significant importance is found only in the relationship between formal impersonal mechanisms and the size of subsidiary. However, our findings produce conflicting evidence. If we use the number of personnel as indicator of size, we observe that the larger the subsidiary, the more centralized procedures it intends to use, since there is a statistical positive association between the number of employees and the instrument "formal reporting systems" and "planning and control of results". This is partially in accordance with the evidence provided by Ambos and Reitsperger (2002), according to which there is a positive relationship between subsidiary size and output control instruments. However, if we examine subsidiaries' volume of sales, we observe a negative relationship between the use of output control mechanisms and subsidiary size.

Geographical distance seems to affect the use of coordination mechanisms. Contrary to our hypothesis, Japanese subsidiaries tend to use more "person-oriented" mechanisms compared with subsidiaries from other Europe and US. This is consistent with evidence supporting that Japanese enterprises coordinate their activities through the use interpersonal mechanisms (Reger, 1999; Hedlund \& Nonaka, 1993). Although it is considered inappropriate to consider European countries as a homogenous whole, it seems that EU and US subsidiaries appear to use other ways to integrate the whole MNE network, focused more on formalized mechanisms, hence making transfers for control less necessary. This is in accordance with Harzing's (2001) argument, according to which American and British MNEs tend to send out expatriates when it is absolutely necessary due to knowledge transfer or the lack of locally qualified personnel. Contrary to our last hypothesis, the only statistical significant relationship verifies the positive correlation between global sectors and cross border visits. As an explanation for that, we could support that the supply of a variety of markets with same products would require negotiations among subsidiaries to accept product mix. No statistical significant relationships have been identified between the variables age and export intensity and the deployment of specific coordination instruments.

\section{CONCLUSIONS}

The international management field boasts a long tradition of research on the link between strategy and structure. Within this context, as MNEs try to balance between the local responsiveness at the subsidiary level and the global integration of operations for global competitiveness, they are required to design their structures and systems to fit the 
contingencies of environment, strategy, technology and so on for survival and success. According to Kim et al. (2003), global integration becomes possible only through the use of organizational mechanisms for coordination and control. It is somewhat surprising, therefore, that so little research has addressed the issue of coordination from the subsidiaries' perspective. This paper adds to this identied gap in the literature by providing empirical evidence on the use of coordination mechanisms in foreign operations located in an EU small open economy. In particular, our aim was two-fold: (a) to develop a classification for coordination mechanisms that will fit our research objectives, and (b) to identify the contextual influences that determine the patterns that manage the interdependencies between HQs and subsidiaries.

Based on both general and global integration literature (e.g. Thompson, 1967; Galbraith, 1973; Martinez and Jarillo, 1989; Kim et al., 2003) our classification distinguishes among five modes for coordinating global activities: technocratic, people (formal and informal), social and technology. Bringing the empirical evidence together, three are the most important implications coming out from our analysis. First, concerning our results for $\mathrm{H} 1-\mathrm{H} 2$ our findings record the existence of a multifaceted network of coordination mechanisms, which is differentiated among the different types of subsidiaries. In this regard, subsidiaries' role and autonomy in decision-making emerge as decisive factors influencing the effective integration of MNE operations. Horizontally integrated foreign operations seem to be subjected to tighter HQs control, whereas the parent multinational retains full control over the whole development process. Thus, subsidiaries granted with the re-application of the group's product range (TMRs), as well as subsidiaries of a more efficiency-seeking nature (RPSs) follow rather centralized and hierarchical organizational patterns, by emphasizing on impersonal and structural procedures, yielding to detach the process of aligning decisions and actions from individuals. When overseas subsidiaries are not conceived as an outlet for the effective application of centrally-generated product technology, but instead play increasingly powerful roles in the creative process themselves, people-based integration modes seem to be more suitable for aligning worldwide operations. Thus, for subsidiaries granted with dynamic mandates (PMs), the rigidity of traditional organizational models supporting that centralized structures and formal coordination patterns are required so as MNEs secure ownership-specific advantages, realize economies of large scale effects and synergies are widely challenged. PMs are likely to collaborate more intensively with local firms and scientific institutions; being in a better position to scan the host environment for relevant 
inputs so as to deal more efficiently with local responsiveness pressures. In this regard, it seems that informal personal mechanisms, corporate culture and IS alignments are well placed within the context of these subsidiaries' strategy and structure.

Based on results for $\mathrm{H} 3-\mathrm{H} 6$ and $\mathrm{H} 8$, we conclude that technology and organizational strategies are inextricably conjoined in the light of the growing international expansion of research activities by MNEs. On the contrary, other factors characterizing the "internal environment" of subsidiaries (years of operation, size, export intensity) have not such "predictive quality". Thus, the design of the international coordination processes for R\&D subsidiaries effective integration within the MNEs relies on the utilization of various modes and instruments. In this context, R\&D subsidiaries respond to the challenge of integrating their national and international activities through a combination of structural, personal, informal and horizontal mechanisms. Finally, the country of MNE origin (H7) seems to influence the appropriate coordination patterns within the network. As such, our result reveal that each region has a distinct set (or a unique ideal profile) of more effective modes for global integration. Our findings demonstrate that the formal impersonal integration mode is viewed as more appropriate for European and US MNEs compared to their Japanese counterparts, whereas the latter rely more on people-based mechanisms for effective coordination and control.

Results should be considered in the light of several limitations. Of particular concern is the fact that the survey is mainly focused on exploring the demand-side factors of determining the efficient integration of global operations and the evidence provided is limited to subsidiaries located in Greece. However, the received wisdom in the management of MNEs suggests that the use of coordination mechanisms is also affected by the distinctive economic, legal, political and cultural environments of the individual host countries. Although we could expect similar findings for middle-income peripheral European countries (where MNEs show a strong tendency for hierarchical control), we should be very cautious in generalizing the results for more advanced economies. Moreover, factors, such as the degree of MNEs' internationalization and the number of foreign subsidiaries could also affect the coordination instruments that integrate foreign operations. Finally, according to the construct of the research we investigate coordination mechanisms individually rather in combination, whereas organizational designs and coordination mechanisms usually coexist in complex and unique ways. We think that future research should be oriented towards the above issues. In addition, there is a need for further investigations to address different research configurations of this sort and the 
effect on subsidiaries' performance. Thus, a more holistic investigation of the topic would require the impact of the usage of different coordination mechanisms on subsidiaries' output. Such approach might include different indicators for performance (such as the effective commercialization of new products, ROE, ROI etc.), dependent on the role of the subsidiaries. Further studies could also include the perspective of the HQs in order to generate a more balanced and comprehensive view of the challenges and the factors associated when coordinating foreign subunits. Moreover, it would be very interesting to examine the use of mechanisms through time and ascribe a dynamic dimension to the study. A more complete understanding of coordination mechanisms can be better founded through longitudinal research designs. We think that future research should be oriented towards the above issues.

In the main, the main purpose of this paper was to provide some insights concerning the coordination patterns of foreign operations. Despite the several limitations of the study and the fact that there is always room for error in any questionnaire-based research, we believe that evidence revealed from the survey fulfils our initial purpose.

\section{REFERENCES}

Agarwal, S., \& Ramaswami, S. (1992). Choice of foreign market entry mode: Impact of ownership, location and internalization factors. Journal of International Business Studies, 23(1), 1-27

Aldrich, H. E. (1979). Organizations and environments. New Jersey: Prentice- Hall, Englewood Cliffs.

Allen, T. J. (1977). Managing the flow of technology. Cambridge, MA: MIT Press

Almeida, P., \& Kogut, B. (1997). The exploration of technological diversity and the geographic localization of innovation. Small Business Economics, 9(1), 21-31.

Ambos, B., \& Reitsperger, W. D (2002). Governing knowledge procedures in MNCs: The case of German R\&D units abroad. Paper presented at the European International Business Academy Conference, Athens: Greece.

Asakawa, K. (2001). Evolving headquarters-subsidiary dynamics in international R\&D: The case of Japanese multinationals. R\&D Management, 31(1), 1-14

Bartlett, C. A., \& Ghoshal S. (1992). Transnational management: Text, cases and readings in cross-border management. New York: McGraw-Hill International Editions.

Bartlett, C. A., \& Ghoshal S. (1990). Managing innovation in the transnational 
corporation. In C. Bartlett, Y. Doz \& G. Hedlund (Eds.), Managing the global firm (pp. 215-255). London: Routledge.

Bartlett, C. A., \& Ghoshal S. (1989). Managing across borders: The transnational solution. Boston, MA: Harvard Business School Press.

Bartlett, C. A., \& Ghoshal S. (1987a). The individualized corporation: A fundamentally new approach to management. New York: Harper Collins.

Bartlett, C. A., \& Ghoshal S. (1987b). Tap your subsidiaries for global reach. Harvard Business Review, 64(6), 87-94.

Barnard, C. (1968). The functions of the executive. Cambridge, MA: Harvard University Press.

Belderbos, R. (2001). Overseas innovations by Japanese firms: An analysis of patent and subsidiary data. Research Policy, 30(2), 313-332.

Birkinshaw, J. (1996). How multinational subsidiary mandates are gained and lost. Journal of International Business Studies, 27, 467-495.

Birkinshaw, J., Nobel, R., \& Ridderstrale, J. (2002). Knowledge as a contingency variable: Do the characteristic of knowledge predict organizational structure?. Organization Science, 13(3), 274-289.

Bjorkman, A., \& Piekkari, R. M. (2002). Hiding behind the language: Language fluency of subsidiary staff and headquarter control in multinational corporations. Paper presented at European International Business Academy Conference, Athens: Greece.

Bouty, I. (2000). Interpersonal and interaction influences on informal resource exchanges between R\&D researchers across organizational boundaries. Academy of Management Journal, 43(1), 50-65.

Brock, D. (2003). Autonomy of individuals and organizations: Towards a strategy research agenda. International Journal of Business and Economics, 2(1), 57-73.

Caves, R. E (1996). Multinational enterprise and economic analysis. Cambridge, MA: Cambridge University Press.

Cespedes, F. (1992). Sales coordination: An exploratory study. Journal of Personal Selling and Sales Management, 12(3), 13-29.

Chang, Y. C. (2003). Benefits of co-operation on innovative performance: Evidence from integrated circuits and biotechnology firms in the UK and Taiwan. R\&D Management, 33(4), 425-437.

Cheng, J. L., \& Bolon, D. S. (1993). The management of R\&D: A neglected topic in international business research. Journal of International Business Studies, 1, 1-18. 
Cray, D. (1984). Control and coordination in multinational corporations. Journal of International Business Studies, 4, 85-98.

Doz, Y. (1987). Strategic management in multinational companies. New York: Pergamon Press.

Doz, Y. \& Prahalad, C. (1984). Patterns of strategic control within MNC corporations. Journal of International Business Studies, 15, 55-72.

Edstrom, A., \& Galbraith, J. (1977). Alternative policies for international transfers of managers. Management International Review, 17(2), 11-22.

Egelhoff, W. G. (1984). Patterns of control in US, UK and European multinational corporations. Journal of International Business Studies, 15, 73-83.

Eriksson, K., Majkgard, A., \& Sharma, D. (2000). Path dependence and knowledge development in the internationalization process. Management International Review, 40(4), 307-328.

Fayol, H. (1949). General and industrial management. London: Pitman.

Fisher, W. A., \& Behrman, J. N. (1979). The coordination of foreign R\&D activities. Journal of International Business Studies, 10(3), 28-35.

Gaba, V., Pan, Y., \& Ungson, G. (2002). Timing of entry in international market: An empirical study of U.S. Fortune 500 firms in China. Journal of International Business Studies, 33(1), 39-56.

Galbraith, J. R. (1973). Designing complex organizations. Reading: Addison-Wesley.

Ghauri, P. N. (1992). New structures in MNCs based in small countries: A network approach. European Management Journal, 10, 357-364.

Gupta, A. K., \& Govindarajan V. (1991). Knowledge flows and the structure of multinational corporations. Academy of Management Review, 4, 768-792.

Govindarajan, V. (1988). A contingency approach to strategy implementation at the business-unit level: Integrating administrative mechanisms with strategy. Academy of Management Journal, 31, 828-853.

Hakanson, L. (1981). Organisation and evolution of foreign R\&D in Swedish multinationals. Geografiska Annaler, 63B, 47-56.

Han A., \& Hausman J. (1990). Flexible parametric estimation of duration and competing risk models. Journal of Applied Econometrics, 5, 1-28.

Harzing, A. W. (2001). An analysis of the functions of international transfer of managers in MNCs. Employee Relations, 23(6), 581-598.

Harzing, A. W. (2000). An empirical test and extension of the Bartlett and Ghoshal 
Typology of multinational companies. Journal of International Business Studies, 31(1), 101-120.

Hedlund, G. (1984). Organization in-between: The evolution of mother daughter structure of managing foreign subsidiaries in Swedish MNCs. Journal of International Business Studies, 15(3), 109-123.

Hedlund, G., \& Nonaka, I. (1993). Models of knowledge management in the West and Japan. In P. Lorange (Ed.), Implementing strategic process: Change, learning and cooperation (pp.117-144). Oxford: Basil Blackwell.

Johanson, J., \& Vahlne, J. E. (1990). The mechanism of internationalization. International Marketing Review, 7, 11-24.

Kiefer, N. M., \& Skoog, G.R (1984). Local asymptotic specification error analysis. Econometrica, 52, 873-855.

Kim, K., Park J. H., \& Prescott J. E. (2003). The global integration of business functions: A study of multinational business in integrated global industries. Journal of International Business Studies, 34(4), 327-344.

Kogut, B., \& Zander, U. (1993). Knowledge of the firm and evolutionary theory of the multinational corporation. Journal of International Business Studies, 24, 625-645.

Korbin, J. (1994). Is there a relationship between a geocentric mindset and multinational strategy?. Journal of International Business Studies, 25(3), 493-511.

Kotabe, M., \& Omura, G. S. (1989). Sourcing strategies of Western and Japanese multinationals: A comparison. Journal of International Business Studies, 20(1), 118.

Kuemmerle, W. (1999). The drivers of foreign direct investment into research and development: An empirical investigation. Journal of International Business Studies, 30(1), 411-432.

Lehrer, M., \& Asakawa, K. (1999). Unbundling European operations: Regional management and corporate flexibility in American and Japanese MNCs. Journal of World Business, 34(3), 267-286.

Lin, B. W. (2003). Technology transfer as technological learning: A source of competitive advantage for firms with limited R\&D resources. R\&D Management, 33(3), 327-341.

Makhija, M. V., Kim, K., \& Williamson S. D. (1997). Measuring globalization of industries using a national industry approach: Empirical evidence across five countries and over time. Journal of International Business Studies, 28(4), 679-710. 
Martinez, J. I., \& Jarillo, J. C. (1991). Coordination demands of international strategies. Journal of International Business Studies, 22(3), 429-444.

Martinez, J. I., \& Jarillo, J. C. (1990). Different roles for subsidiaries: The case of multinational corporations in Spain. Strategic Management Journal, 11, 501-512.

Martinez, J. I., \& Jarillo, J. C. (1989). The evolution of research on coordination mechanisms in multinational corporations. Journal of International Business Studies, 20(3), 489-514

McCann, J. E., \& Galbraith, J. R. (1981). Interdepartmental relations. In P.C. Nystrom, \& W. H. Starbuck (Eds.), The handbook of organizational design, Vol. 2 (pp. 60-84). New York: Oxford University Press.

Mintzberg, H. (1979). The structuring of organizations. New York: Prentice-Hall.

Mittelstaedt, J., Harben, G., \& Ward, W. (2003). How small is too small? Firm size as a barrier to exporting from the United States. Journal of Small Business Management, 41(1), 68-84.

Morrison, A., \& Roth K. (1992). A taxonomy of business level strategies in global industries. Strategic Management Journal, 13, 399-418.

Murphy, A. (1996). Simple LM tests of mis-specification for ordered logit models. Economic Letters, 52, 137-141.

Murray, A. J. (1988). A contingency view of Porter's generic strategies. Academy of Management Review, 13, 390-400.

Nohria, N., \& Ghoshal, S. (1997). The differentiated network: Organizing multinational corporations for value creation. San Francisco: Wiley.

Odagiri, H., \& Yasuda, H. (1996). The determinants of overseas R\&D by Japanese firms: An empirical study at the industry and company levels. Research Policy, 25(7), 1059-1079.

Papanastassiou, M., \& Pearce, R. (1999). Multinationals, technology and national competitiveness. London: Cheltenham Elgar.

Papanastassiou, M., \& Pearce, R., (1997). European markets and the strategic roles of multinational enterprise subsidiaries in the UK. Journal of Common Market Studies, 35(2), 243-266.

Papanastassiou, M., \& Pearce, R. (1994). The internationalization of research and development by Japanese enterprises. R\&D Management, 24(2), 155-165.

Pearce, R. (1999). The evolution of technology in multinational enterprises: The role of creative subsidiaries. International Business Review, 8, 125-148. 
Penner-Hahn, J. (1998). Firm and environmental issues on the mode and sequence of foreign research activities. Strategic Management Journal, 19, 149-168.

Porter, M. (1986). Changing patterns of international competition. California Management Review, 27, 9-40.

Prahaland, C. K., \& Doz, Y. L. (1987). The multinational mission: Balancing local demand and global vision. New York: Free Press.

Pugh, D. S., Hickson, D. K., Hinings, C. R., \& Turner, C. (1968). Dimensions of organization structure. Administrative Quarterly Journal, 13, 15-26.

Quester, P., \& Conduit, J. (1996). Standardization, centralization and marketing in multinational companies. International Business Review, 5(4), 395-421.

Reger, G. (1999). How R\&D is coordinated in Japanese and European multinationals. R\&D Management, 29(1), 71-88.

Reger, G. (1997). Internalization and coordination of R\&D of Western, European and Japanese multinational corporations. Paper presented at European International Business Academy, Stutgart: Germany.

Sawhney, M., \& Prandelli, E. (2000). Communities of creation: Managing distributed innovation in turbulent markets. California Management Review, 42(2), 24-54.

Taggart, J. H. (1997). An evolution of the integration-responsiveness framework: MNC manufacturing subsidiaries in the UK. Management International Review, 37(4), 295-318.

Tavares, A. T., \& Young, S. (2002). Explaining the export intensity of multinational subsidiaries: An EU-based empirical study. Paper presented at European International Business Academy Conference, Athens: Greece.

Thompson, J. D. (1967). Organizations in action: Social science bases of administrative theory. New York: McGraw Hill.

Van de Ven A. H., Delbecq A. L., \& Koening, R. (1976). Determinants of coordination models within organizations. American Sociology Review, 41, 322-338.

White, R., \& Poynter, T. (1984). Strategies for foreign owned subsidiaries in Canada. Business Quarterly, 48(4), 59-69.

Wolf, J. (1996). Coordination patterns in international human resource management. Paper presented at European International Business Academy Conference, Firenze: Italy. 


\section{Appendix I: Questions used in the survey}

\section{BACKGROUND OF THE SUBSIDIARY}

1. When was the company established in Greece?

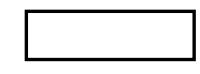

2. Which is the country of HQs origin?

3. Which is the sector of subsidiary activity?

4. How many personnel does it employ?

5. What was the sales/turnover of the subsidiary the last year?

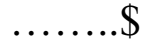

6. What proportion of the production was exported last year?

7. Does the subsidiary have its own laboratory to support its operations?

\section{ROLES OF SUBSIDIARY}

8. Please grade each of the following roles in terms of their importance in your operations as:

(1) our only role

(2) our predominant role

(3) a secondary role

(4) not a part of our role

(a) to produce for Greece products that are already established in our MNE group's product range

(b) to play a role in the MNE group's European supply network by specializing in the production and export of part or of component parts of the established product range

(c) to develop, produce and market for Greece and/or

European or wider markets new products additional to the

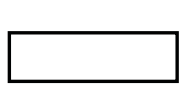
MNE group's existing range 


\section{ORGANIZATIONAL CHARACTERISTICS}

9. Where the critical strategic decisions for the subsidiary are taken? (tick the more relevant)

(a) Decisions are mainly taken by the subsidiary's BoD

(b) Decisions are mainly taken by the subsidiary's BoD after

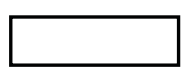
consulting the HQs

(c) Decisions are mainly taken by the HQs after consulting the subsidiary's BoD

(d) Decisions are mainly taken by the HQs

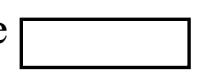

10 How important are the factors listed below to the co-ordination of your activities (Please grade each as being:)

(1) very important

(2) important

(3) not so important

(4) not taken under consideration
(a) formal reporting systems
(b) control of output
(c) international transfer of managers
(d) cross - border visits
(e) strategic teams
(f) training teams
(f) corporate culture
(g) corporate networks

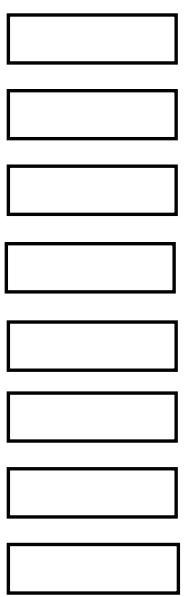




\section{Appendix II: Correlation Matrix}

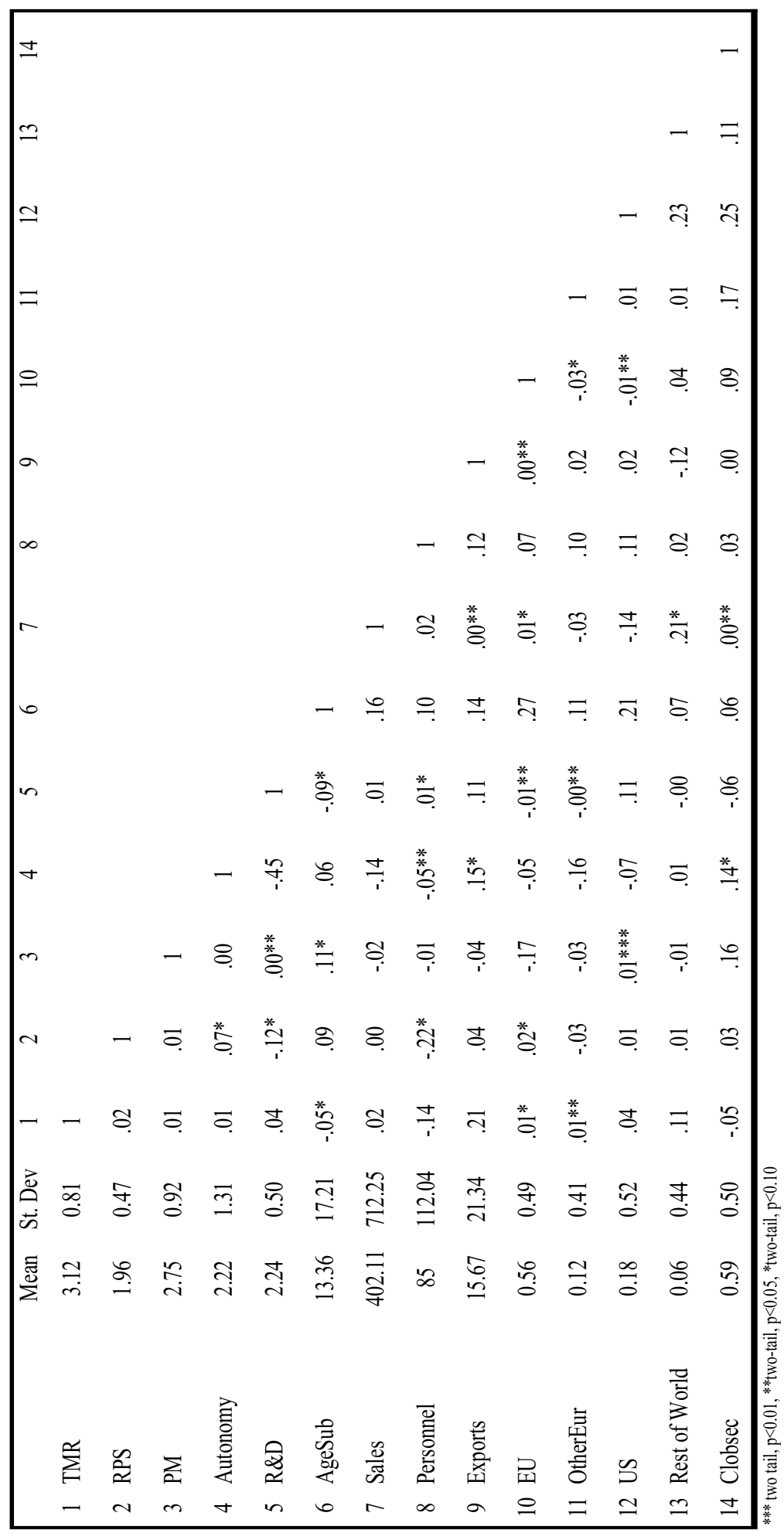

